\title{
Waste Colored Glasses as Sintering Aid in Ceramic Tiles Production
}

\author{
Jiann-Yang Hwang*, Xiaodi Huang, Adele Garkida, and Allison Hein \\ Detartment of Materials Science and Engineering \\ Michigan Technological University \\ Houghton, Michigan, 49931 \\ *Corresponding author: E-mail jhwang@mtu.edu
}

\begin{abstract}
Bentonite, kaolin and Montmorillonite were mixed with $0 \%, 2 \%, 5 \%$ and $10 \%$ by weight additions of mixed color post consumer glass to determine their softening points. And then to determine the effects of glass addition on clay firing, Acustar tinted tempered, Acustar GL-20 and post consumer mixed were used. Six glass samples were produced; 150 micron and 5 micron tinted tempered, 150 micron and 5 micron GL-20 and 150 micron and 5 micron post consumer mix. Bentonite clay was used to mix with these glasses at $0 w t \%, 2 w t \%, 5 w t \%, 10 w t \%, 25 w t \%$ and $50 w t \%$ and $5 \%$ water was added. The resulting composite blends were then die pressed at 3200 psi to produce rectangular specimens with cross sections of 1.25" x 0.5 ”. Each specimen weighed approximately 2.5 grams and they were fired at $800^{\circ} \mathrm{C}, 900^{\circ} \mathrm{C}, 1000^{\circ} \mathrm{C}$ and $1100^{\circ} \mathrm{C}$ in a lindberg box furnace in air. The firing result showed that the addition of only a small percentage of post consumer glass lowers the melting points of clays by $50^{\circ} \mathrm{C}$ to $150^{\circ} \mathrm{C}$. As a result of this the energy consumed to produce the clay products was reduced and the amount of reduction varied from clay to clay. Different size glass particles also resulted in considerably different effects on the clay sintering properties.
\end{abstract}

Keywords: Sintering Aid; Firing Temperature; Ceramic Tiles

\section{INTRODUCTION}

A lower softening point material is potentially capable of reducing the firing temperature of clay products such as bricks and tiles through a chemical reaction with the clay. The pioneer work done by M.E Tyrell et al at the Tuscaloosa Metallurgy Research Laboratories has shown the benefit of adding waste glass powder in clay. The addition of glass reduces firing temperature and time resulting in a significant increase in production without additional heating capability of a plant ${ }^{1}$. Considering the United States production of about 20 million tons of building bricks ${ }^{2}$, a small amount of glass additive represents a large utilization of waste glass. Besides the potential for the utilization of a large volume of glass, mixed color is acceptable in many clay products. Small amounts of color variation are not critical in many applications as glazing on the surface of clay products covers the clay body disguising its original color. 
In their research, Tyrell et al mixed minus 20, 48, 100, 150 and 200 mesh (850, 300, 150, 106 and 75 micron) glass with clay using clay to glass ratio of $60 \mathrm{wt} \%$. Their results showed that -200 mesh (75 microns) gave the best results. Tyrell and his co-workers also tested $10 w t \%$, 20wt\%, 30wt\%, 40wt\%, 50wt\% and 70wt \% glass addition in clay. Their conclusions were that higher loading of glass resulted in a lower melting temperature of the clay ${ }^{3}$.

In another study soda-lime float or container glass was introduced, in replacement of soda feldspar in typical porcelain stoneware bodies (up to $10 \mathrm{wt} \%$ ) that underwent a laboratory simulation of tile making process, with a technological and compositional characterization of both fired and unfired tiles. Soda-lime glass had no significant effect on semi-finished products, but it influenced remarkably the firing behavior, increasing shrinkage and closed porosity, decreasing open porosity and bulk density, and lowering mechanical and tribological performances ${ }^{4}$.

Usually the final stages of sintering are optimized via residual porosity and grain size and shape (that are believed to control mechanical characteristics) with the help of temperature and time of sintering. Elimination of residual porosity at final stage of sintering may be accompanied by excessive grain growth. Grain growth may take place as a result of secondary recrystallization during solid state sintering. During sintering in the presence of a liquid phase, grain growth may be a result of "dissolution-precipitation" mechanism, as well as a result of direct coalescence owing to migration of solid-solid boundaries ${ }^{5}$.

Glass addition to other types of ceramics has also contributed to their sintering aid as seen in the test with two commercially available glasses, $\mathrm{PbO}-\mathrm{B}_{2} \mathrm{O}_{3}-\mathrm{SiO}_{2}$ (GA-9) and $\mathrm{ZnO}-\mathrm{B}_{2} \mathrm{O}_{3}-\mathrm{SiO}_{2}(\mathrm{GP}-032)$ which have been also been found to improve the sintering property of $\mathrm{La}_{4} \mathrm{Ti}_{9} \mathrm{O}_{24}$ ceramics. Above 20 vol. \% of respective GA-9/GP-032 addition, $\mathrm{La}_{4} \mathrm{Ti}_{9} \mathrm{O}_{24}$ ceramics with $95 \%$ of the theoretical density were obtained at a relatively low temperature of $1000{ }^{\circ} \mathrm{C}$, compared to the sintering temperature of $1350{ }^{\circ} \mathrm{C}$, for preparing pure $\mathrm{La}_{4} \mathrm{Ti}_{9} \mathrm{O}_{24}$ bulks with a similar density ${ }^{6}$. Sintering of undoped $\mathrm{Ba}\left(\mathrm{Mg}_{1 / 3} \mathrm{Ta}_{2 / 3}\right) \mathrm{O}_{3}$ (BMT) ceramics at $1500{ }^{\circ} \mathrm{C}$ gives BMT ceramics with $96.0 \%$ theoretical density and an ordering structure, but the satellite phases of $\mathrm{Ba}_{5} \mathrm{Ta}_{4} \mathrm{O}_{15}, \mathrm{Ba}_{4} \mathrm{Ta}_{2} \mathrm{O}_{9}, \mathrm{Ba}_{7} \mathrm{Ta}_{6} \mathrm{O}_{22}$, and $\mathrm{Mg}_{4} \mathrm{Ta}_{2} \mathrm{O}_{9}$ are difficult to eliminate completely. The addition of $\mathrm{MgO}-\mathrm{CaO}-\mathrm{Al}_{2} \mathrm{O}_{3}-\mathrm{SiO}_{2}$ (MCAS) glass as a sintering aid not only decreases the satellite phases of $\mathrm{Ba}\left(\mathrm{Mg}_{1 / 3} \mathrm{Ta}_{2 / 3}\right)$ $\mathrm{O}_{3}$ (BMT) ceramics but also improves the sinterability of BMT ceramics. The densification of the BMT ceramics can be performed well at lower temperatures of 1300$1350{ }^{\circ} \mathrm{C}$ by the addition of 3 wt.\% MCAS - 6 wt.\% MCAS used as a sintering aid with the lower temperature resulting from the higher amount of the glass ${ }^{7}$. For MCAS-doped $\mathrm{BaTi}_{4} \mathrm{O}_{9}$ and $\mathrm{Ba}_{2} \mathrm{Ti}_{9} \mathrm{O}_{20}$ ceramics the major phases are $\mathrm{BaTi}_{4} \mathrm{O}_{9}$ and $\mathrm{Ba}_{2} \mathrm{Ti}_{9} \mathrm{O}_{20}$, cordierite is observed as minor phase, the temperatures needed to densify the $\mathrm{BaTi}_{4} \mathrm{O}_{9}$ and $\mathrm{Ba}_{2} \mathrm{Ti}_{9} \mathrm{O}_{20}$ ceramics are lowered down with the increase amount of MCAS glass addition $^{8}$.

The relative particle sizes of clay and waste glass powders are also important. Clay is a very fine powder in the micron size range, often with a substantial amount of sub-micron size particles. Clay is an alumino-silicate compound and originates from a number of 
different geographic locations that vary in composition and particle size. This study used three alumino-silicate materials of bentonite, kaolin and montmorillonite to mix with waste glass for testing of their softening points. The waste glasses selected included Acustar tinted tempered, Acustar GL-20 and post consumer glasses to test for their sintering effect on Bentonite. Two sizes of glass 150 micron and 5 micron were used to evaluate the size effect on clay firing at various clay and glass mixture ratios.

\section{METHODS}

The initial research task involved determining the softening points of bentonite, kaolin and montmorillonite with $0 \%, 2 \%, 5 \%$ and $10 \%$ by weight additions of mixed color post consumer glass. The mixed color glass consisted of $4.5 \mathrm{wt} \%$ amber, $13.5 \mathrm{wt} \%$ green and $82 \mathrm{wt} \%$ clear, that was the ratio found in the waste stream collected for this project. The PCE (pyrometric cone equivalent) softening points of these materials were determined according to ASTM Standard C24 "Test Method for Pyrometric Cone Equivalent (PCE) of Refractory Materials". To evaluate the effects of the glass addition on clay firing, three glasses Acustar tinted tempered, Acustar GL-20 and color post consumer glass were used. A total of six glass samples were produced; 150 micron and 5 micron tinted tempered, 150 micron and 5 micron GL-20 and 150 micron and 5 micron post consumer mix. Bentonite clay was used to mix with these glass samples at $0 w t \%$, $2 w t \%$, $5 w t \%$, $10 w t \%, 25 w t \%$ and $50 w t \%$. During the mixing of the clay and glass $5 w t \%$ water was added, the resulting composite blends were then die pressed at 3200psi to produce rectangular specimens with cross sections of 1.25 ” x 0.5 ”. Each specimen weighed 2.5 grams. The pressed specimens were then fired at $800^{\circ} \mathrm{C}, 900^{\circ} \mathrm{C}, 1000^{\circ} \mathrm{C}$ and $1100^{\circ} \mathrm{C}$ in a lindberg box furnace in air. Firing shrinkage was determined by measuring the physical dimensions of the specimens before and after firing. The apparent porosity, water of absorption, apparent specific gravity and bulk density were determined according to ASTM C373 “Test Method for apparent porosity, water absorption, apparent specific gravity and bulk density of fired whiteware products”. The fracture surfaces of the specimens were observed using a JEOL JSM 820 Scanning Electron Microscope (SEM).

\section{RESULTS AND DISCUSSION}

\section{PCE Test}

The PCE test results are presented in table 1 . The results indicate that the addition of only a small percentage of post consumer glass reduced the softening points of clays. Addition of $10 \mathrm{wt} \%$ post consumer glass reduced the softening points of bentonite, kaolin and montmorillonite by $50^{\circ} \mathrm{C}, 50^{\circ} \mathrm{C}$ and $150^{\circ} \mathrm{C}$ respectively. The reduction on softening point by the addition of post consumer glass is more profound with montmorillonite than with bentonite or kaolin.

\section{Shrinkage}

The ability to predict the shrinkage behavior of a clay product during sintering is imperative for a manufacturer. One has to be able to predict shrinkage rates to determine 
the dimensions of a final product. A lower shrinkage is always preferred if other properties can be achieved. The shrinkage behavior of the clay specimens with different glass samples and various loading levels sintered at $800^{\circ} \mathrm{C}, 900^{\circ} \mathrm{C}, 1000^{\circ} \mathrm{C}$ and $1100^{\circ} \mathrm{C}$ are shown in figures 1-8. In this discussion the following nomenclature is used; $0.02 \mathrm{TT}$ represents $2 \%$ tinted glass addition, 0.02 PC represents $2 \%$ post consumer glass addition, 0.02 GL represents $2 \%$ GL-20 glass addition and so on. The mean shrinkage is defined as the average of shrinkage in length and width.

The shrinkage after sintering at $800^{\circ} \mathrm{C}$ increased as the glass content increased for all the 150 micron and 5 micron TT, PC and GL glasses (figure 1). The results also show that the finer ( 5 micron) glass exhibited twice the shrinkage of the coarse (150 micron) glass in compositions. The greater amount of shrinkage implies that a more absolute chemical reaction between clay and glass took place. And there was no significant difference in shrinkage among the three different types of glasses.

The shrinkage after sintering at $900^{\circ} \mathrm{C}$ was considerably different from that obtained from the $800^{\circ} \mathrm{C}$ sintering tests (figures $2 \& 6$ ). The shrinkage of the specimens with 150 micron glass increased as glass content increased from $0 \mathrm{wt} \%$ to $2 \mathrm{wt} \%$ and then decreased as glass content increased from $2 \mathrm{wt} \%$ to $50 \mathrm{wt} \%$. Sintering shrinkage is mainly determined by sintering temperature, particle size and packing density. Higher temperature provides better kinetics for atom diffusion to reduce the larger surface area of the finer particles. The larger surface area is of a higher free energy, thus making the material thermodynamically unstable. Higher sintering temperature normally leads to higher shrinkage. Finer particles restore more energy thus they tend to have more shrinkage at a faster rate at the same sintering temperature than do coarser particles. The glass particles being 150 micron in size were much larger than the clay particles this may have resulted in a higher packing density with increasing glass content thereby decreasing the sintering shrinkage. On the other hand the shrinkage of the specimens with 5 micron glass increased as the glass content increased from $0 \%$ to $5 \%$ and then started dropping. But when the glass content increased from $25 \%$ to $50 \%$ the shrinkage increased again and all the three samples showed a similar trend.

At $1000^{\circ} \mathrm{C}$ the softening point of clay was being approached and the glass particles began to lose their effect on reducing clay sintering temperature. Figure 3 shows that the shrinkage of specimens with 150 micron glass increased first, then decreased and then increased again as the glass content increased. This is similar to the phenomenon found on the specimens with 5 micron glass sintered at $900^{\circ} \mathrm{C}$ and may be explained in a similar way. Figure 7 gives the shrinkage results of the specimens with 5 micron glass, the shrinkage increased first, then decreased and finally increased again as the glass content increased. The dominant factor may be different at different conditions causing the shrinkage fluctuations. One particular noticeable attribute is the high shrinkage rates for the three specimens at $50 \%$ glass. This may be due to the lower packing density because of the narrower size distribution of clay and glass particles and fine particle size of the glass. In general finer glass resulted in larger shrinkage, which might have included the effect on reducing sintering temperature by reaction with clay and the effect on packing density. 
Sintering at $1100^{\circ} \mathrm{C}$ came even closer to the softening temperature of clay of $1150^{\circ} \mathrm{C}$. The sintering results for the specimens with 150 micron glass are given in figure 4 while those of 5 micron are shown in figure 8 . These results showed that there was some strong reaction between the clay and glass particles. The clay shrinkage was fairly large without the glass additions, approximately $11 \%$. When the glass was added into clay the specimens shrunk less and even expanded as the glass content increased from $2 \mathrm{wt} \%$ to $10 \mathrm{wt} \%$, the specimens appeared to have bubbles protruding from the exterior and these bubbles have been formed due to a chemical reaction. Further examination determined that some bubbles that had been trapped in the specimens either caused less shrinkage or expansion. When the glass content reached $25 \%$ the bubbles found a way to escape because of the lower viscosity of clay and glass mixture at the temperature. When the glass content was increased further to $50 \%$ the specimen melted.

\section{Open Pore, Porosity, Water Absorption and Density}

Open pore, porosity, water absorption and density data of the specimens of were measured and these four properties are related to each other. The amount of water absorption is more important from an application point of view and so the effects of sintering temperature, glass type, glass content and glass particle size on water absorption are therefore illustrated in figures 9 to 16.

At $800^{\circ} \mathrm{C}$ sintering temperature, the water absorption of both series of specimens with 150 micron and 5 micron glass decreased as the glass content increased as shown in figures 9 and 13. The coarser glass seemed to have more of an effect on reducing water absorption than the finer glass, this effect could be due to the higher packing density of the coarser glass with the clay particles. There were no obvious differences between different glass samples.

Specimens with 150 micron glass at $900^{\circ} \mathrm{C}$ sintering temperature showed a decrease in water absorption as the glass content increased. While the water absorption of the specimens with 5 micron decreased as the glass content increased when the glass content was less than $5 \%$ and when it was higher than $5 \%$ the water absorption increased as shown in figures 10 and 14.

The water absorption test results for the specimens sintered at $1000^{\circ} \mathrm{C}$ are given in figures 11 and 15. The noticeable feature of the water absorption curves for the specimens with 150 micron glass and those with 5 micron glass was that the water absorption stopped decreasing when the glass content was around 25\%. The specimens with 5 micron glass exhibited the same tendency and in making reference to the shrinkage curves in figures 1 and 2, the specimens with $25 \%$ of either 150 micron or 5 micron glass had the lowest shrinkage, which implies that there may be some reaction that had happened to form voids stopping shrinkage and increasing water absorption.

Specimens sintered at $1100^{\circ} \mathrm{C}$ for both 150 micron and 5 micron glass had their peak water absorption at a glass content of 5\% (figures 12 and 16). Shrinkage information on these specimens in figures 4 and 8 reveal that there were reactions which formed bubbles, 
that were trapped in the specimen bodies and these bubbles caused more water absorption.

\section{Microstructure}

The microstructures of three pairs of specimens were examined using the SEM. All specimens contained $25 \%$ glass, either 150 micron or 5 micron sizes. These three pairs were sintered at $800^{\circ} \mathrm{C}, 900^{\circ} \mathrm{C}$ and $1000^{\circ} \mathrm{C}$ respectively. There may be some differences between the specimens with 150 micron and 5 micron glass, but it was difficult to determine from the SEM photographs. Figures 17 -22 show the fracture surfaces of these specimens.

Sintering at $800^{\circ} \mathrm{C}$ resulted in particle bonding that was not sufficient. It was not also clear whether a reaction occurred between the clay and the glass particles (figures 17 and 18). After sintering at $900^{\circ} \mathrm{C}$, larger particles with smooth clean surfaces appeared. An energy dispersive spectrum analysis on the particles revealed that their compositions were between glass and clay indicating that the large particles were the products of glass and clay Reaction (figures 19 and 20). Careful searching found wetting of some very small particles with the large ones particularly as shown in figure 19 and this possibly represented the midpoint of the reaction. After sintering at $1000^{\circ} \mathrm{C}$, large particles also dominated (figures 21 and 22). A reaction occurred as most of the 75 wt\% fine clay particles were not present in the sample. However as shown in figure 22 a number of clay particles were still visible. This appears to have been caused by inhomogeneous mixing.

\begin{tabular}{|l|l|}
\hline Table 1 PCE Test results \\
\hline Specimen & Softening Point \\
\hline Bentonite $+0 \%$ Post Consumer Mix Glass & $1150^{\circ} \mathrm{C}$ \\
\hline Bentonite $+2 \%$ Post Consumer Mix Glass & $1150^{\circ} \mathrm{C}$ \\
\hline Bentonite $+5 \%$ Post Consumer Mix Glass & $1150^{\circ} \mathrm{C}$ \\
\hline Bentonite $+10 \%$ Post Consumer Mix Glass & $1100^{\circ} \mathrm{C}$ \\
\hline Kaolin $+0 \%$ Post Consumer Mix Glass & $1400^{\circ} \mathrm{C}$ \\
\hline Kaolin $+2 \%$ Post Consumer Mix Glass & $>1350^{\circ} \mathrm{C}<1400^{\circ} \mathrm{C}$ \\
\hline Kaolin $+5 \%$ Post Consumer Mix Glass & $>1350^{\circ} \mathrm{C}<1400^{\circ} \mathrm{C}$ \\
\hline Kaolin $+10 \%$ Post Consumer Mix Glass & $1350^{\circ} \mathrm{C}$ \\
\hline Montmorillonite $+0 \%$ Post Consumer Mix Glass & $1250^{\circ} \mathrm{C}$ \\
\hline Montmorillonite $+2 \%$ Post Consumer Mix Glass & $1200^{\circ} \mathrm{C}$ \\
\hline Montmorillonite $+5 \%$ Post Consumer Mix Glass & $1150^{\circ} \mathrm{C}$ \\
\hline Montmorillonite $+10 \%$ Post Consumer Mix Glass & $1100^{\circ} \mathrm{C}$ \\
\hline
\end{tabular}

Figures 1-8. Shrinkage Test Results

Figures 9-16 Water Absorption Test Results 


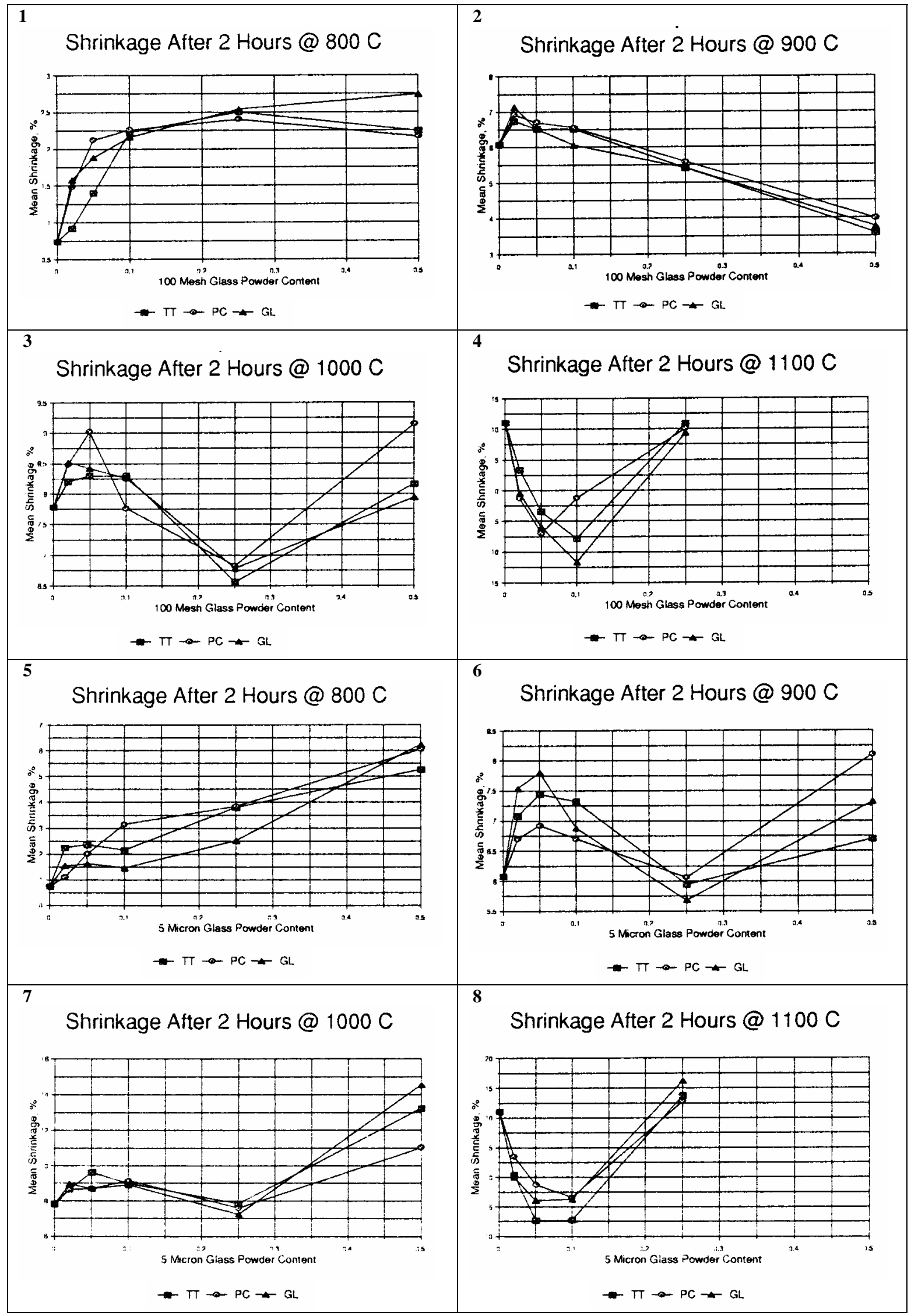




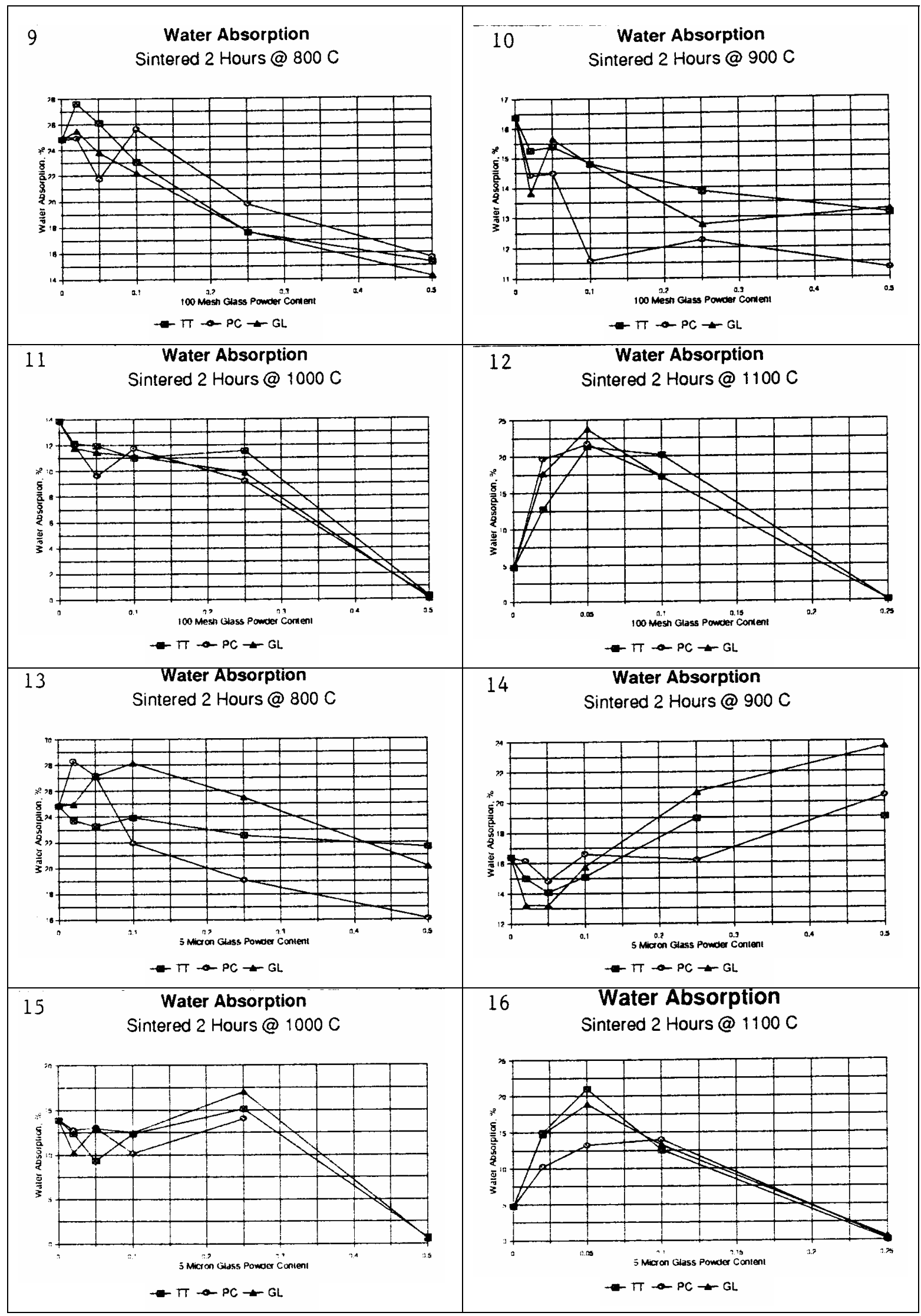




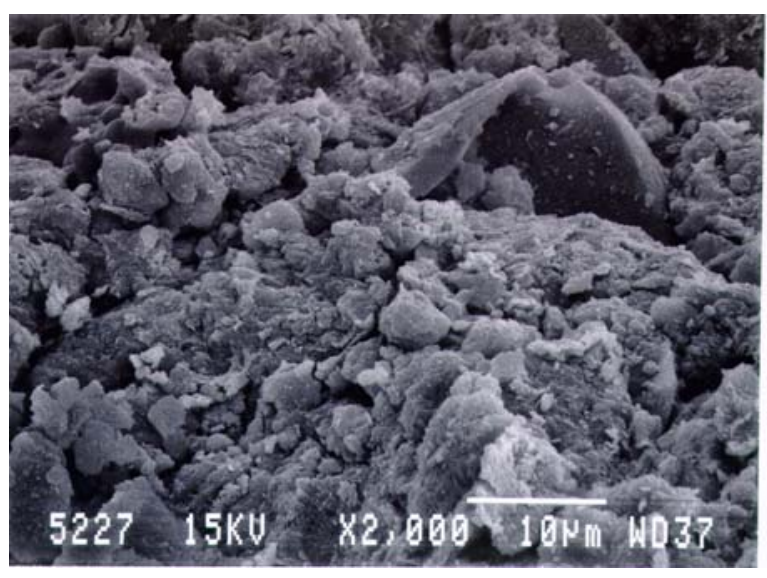

Figure 17. Fracture surface of sample containing $25 \% 150$ micron glass sintered at $800{ }^{\circ} \mathrm{C}$

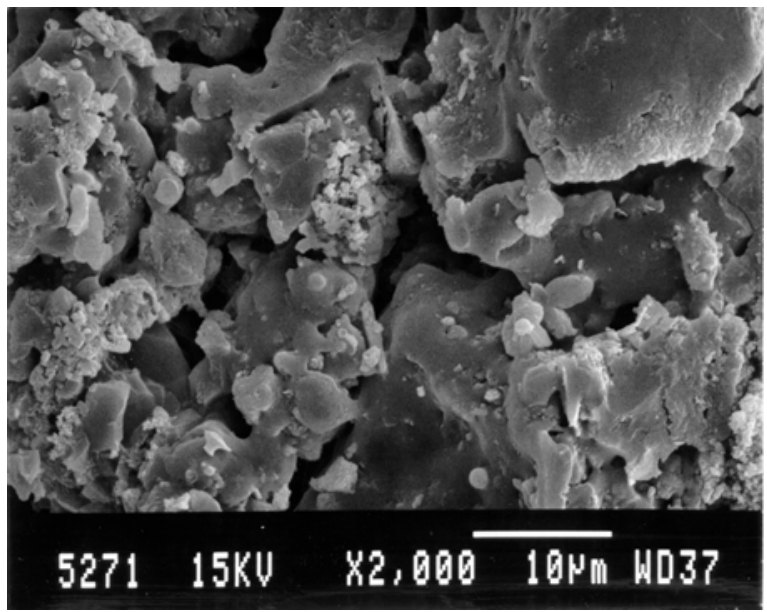

Figure 19 Fracture surface of sample containing $25 \% 150$ micron glass sintered at $900{ }^{\circ} \mathrm{C}$

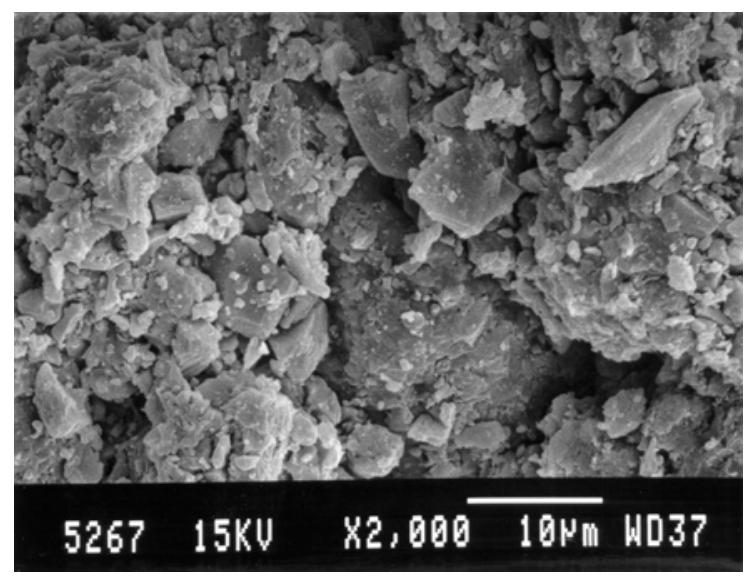

Figure 18. Fracture surface of sample containing $25 \% 5$ micron glass sintered at $800{ }^{\circ} \mathrm{C}$

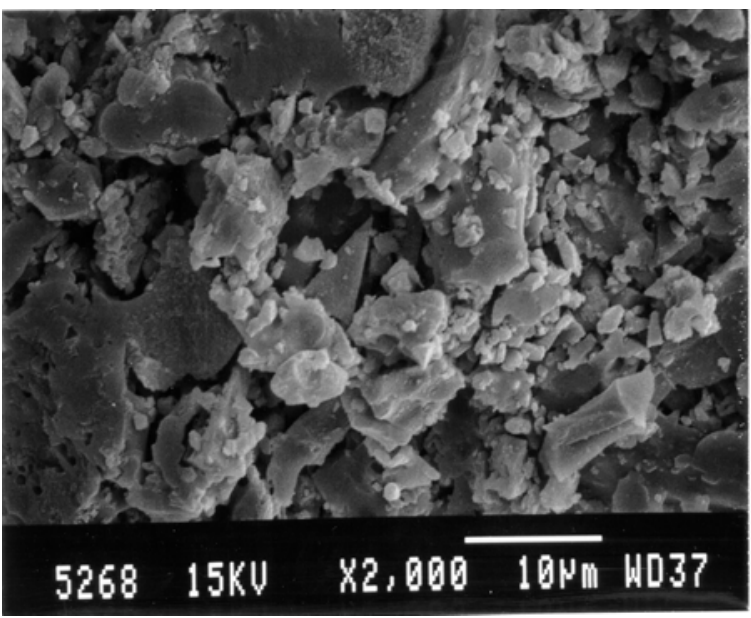

Figure 20 Fracture surface of sample containing $25 \% 5$ micron glass sintered at $800{ }^{\circ} \mathrm{C}$ 


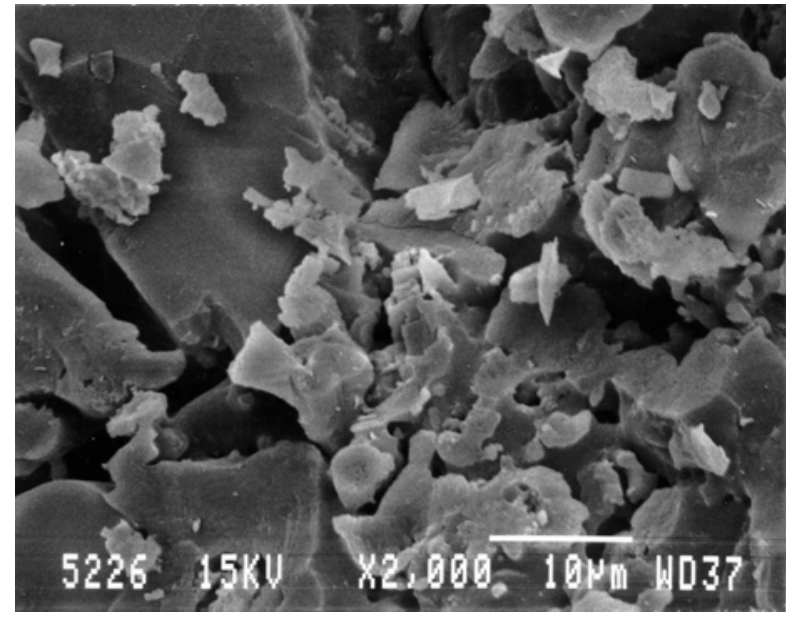

Figure 21. Fracture surface of sample containing $25 \% 150$ micron glass sintered at $1000{ }^{\circ} \mathrm{C}$

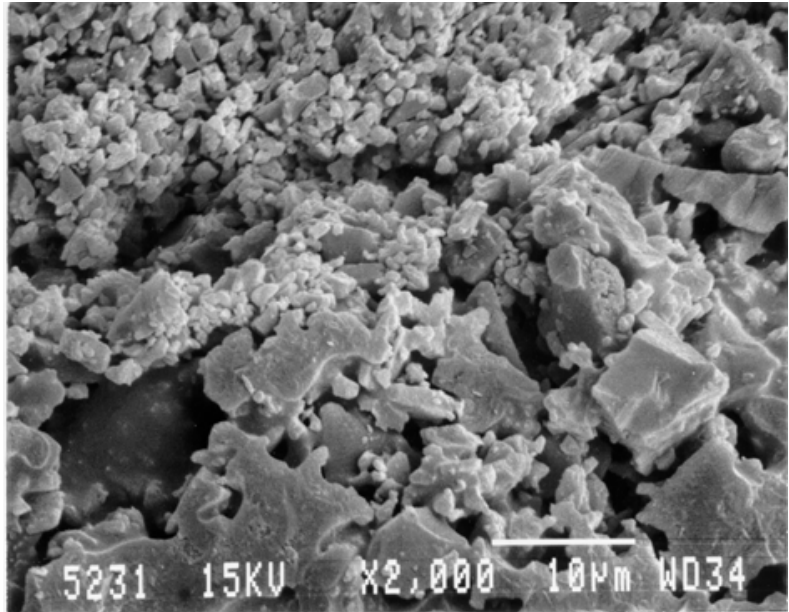

Figure 22 Fracture surface of sample containing $25 \% 5$ micron glass sintered at $1000{ }^{\circ} \mathrm{C}$

\section{CONCLUSION}

This study showed that scrap glass was not only able to be utilized in clay products but also benefits production by reducing firing temperatures. Addition of a small percentage of scrap glass can reduce the clay softening point from $50^{\circ} \mathrm{C}$ to $150^{\circ} \mathrm{C}$ and this amount of reduction is different for different clays. There was no major difference between window glass and post consumer glass being utilized in clay products.

At a relatively lower firing temperature of $800^{\circ} \mathrm{C}$ more glass addition resulted in larger shrinkage and denser materials that absorb less water. At higher firing temperatures the scrap glass addition affects the clay in a more complicated way. 5 micron and 150 micron scrap glass samples showed considerably different effects on clay sintering properties.

\section{REFERENCES}

1. Tyrell M.E, Feld I.L and Barclay J.A: Fabrication and Cost Evaluation of Experimental Building Brick from Waste Glass, Report Investigation o7605, Bureau of Mines 1972.

2. Tyrell M.E amd Goode A.H: Waste Glass as a Flux for Brick Clays; Report of Investigations 7701n Bureau of Mines 1972

3..Matteucci F. Dondi M and Guarini: Effect of Soda-Lime Glass on Sintering and Technological Properties of Porcelain Stoneware Tiles; Ceramics International Volume 28 number 82002 pp 873-880 by Elsevier Science limited access online march 32006

4. Yurkov A. L, Sarkisyan T. A, Ivanov D. A. and Bradt R. C: Final stages of sintering of ceramic materials: Effect of residual porosity and microstructure on mechanical characteristics of surface; Ceramics International Volume 23 Number 51997 pp 389-399 by Elsevier Science limited accessed online march 32006. 
5. Yuan-Wen Liu and Pang Lin: Effects of glass additions on microstructure and microwave dielectric properties of $\mathrm{La}_{4} \mathrm{Ti}_{9} \mathrm{O}_{24}$ Ceramics, Materials Chemistry and Physics Volume 92 Number 92 2005, pp 98-103 by Elsevier Science limited accessed online march 32006.

6. Chien-Min Cheng, Yuan-Tai Hsieh and Cheng-Fu Yang: Effect of glass doping for the sinterability of $\mathrm{Ba}\left(\mathrm{Mg}_{1 / 3} \mathrm{Ta}_{2 / 3}\right) \mathrm{O}_{3}$ ceramics; Journal of Materials Processing Technology Volume 59 number 41996 pp 297-302

7.Chien-Min Cheng, Yuan-Tai Hsieh and Cheng-Fu Yang: Effect of glass doping for the sinterability of $\mathrm{Ba}\left(\mathrm{Mg}_{1 / 3} \mathrm{Ta}_{2 / 3}\right) \mathrm{O}_{3}$ ceramics; Journal of Materials Processing Technology Volume 59 number 41996 pp 297-302

8. Chien-Min Cheng, Cheng-Fu Yang, Shi-Hong Lo and Tseung-Yuen Tseng: Sintering $\mathrm{BaTi}_{4} \mathrm{O}_{9} / \mathrm{Ba}_{2} \mathrm{Ti}_{9} \mathrm{O}_{20}$-based ceramics by glass addition; Journal of the European Ceramic Society, Volume 20 number 8 pp 1061-1067 